Journal of Social and Development Sciences

Vol. 3, No. 9, pp. 322-330, Sep 2012 (ISSN 2221-1152)

\title{
Person-Centered Therapy and Personal Growth
}

\author{
Boontarika Narknisorn \\ Kasetsart University, Thailand \\ bnarknisorn@gmail.com
}

\begin{abstract}
Person-centered therapy enhances humans' personal growth toward self-actualization and deepens quality personal relationship. This article aims to (1) explain the concepts of person-centered therapy and (2) link its contribution to humans' personal growth and healthy relationship. Personcentered therapy believes in human's positive qualities as being trustworthy and owning 'inner resources' to pursue 'self-actualization and health.' The therapeutic goals are to assist clients to be true to themselves and acquire their full potentials. Person-centered therapy emphasizes the qualities of the therapist and therapeutic relationship as the most powerful components to help clients grow. The therapist needs to maintain positive attitudes, to believe in client's potentials and motivation to become actualized, to accept one's and others' uniqueness and needs and to be trustworthy, warm, open and kind. Person-centered therapy reflects that pain and obstacles in life are necessary and can stimulate humans to grow. Person-centered therapy helps the therapist; clients and humans pursue self-actualization and possess better humans' qualities, which can contribute to world peace as Rogers hoped.
\end{abstract}

Key words: Person-centered therapy, personal growth, Carl Rogers, self-actualization, humanistic psychology

\section{Introduction}

Background: Person-centered therapy can be mentioned in other terms as 'client-centered counseling or nondirective, humanistic, Rogerian and Self theory' (Kottler \& Brown, 2000). The person-centered therapy bases its concepts on humanistic psychology (Corey, 2005) which views humans positively. Carl Rogers is a pioneer of person-centered therapy. He created his theory that reflected his ways to overcome struggles in his own personal life. He believed that humans are 'trustworthy' and have their own potentials to understand themselves, deal with their issues, pursue 'changes' and personal growth toward 'self-actualization tendency.' Rogers believed in the power of the therapist's and therapeutic relationship's qualities which can provide the condition for clients to grow. Person-centered therapy enhances both therapist's and clients' personal growth (Corey, 2005) and it can be applied to humans' positive qualities and healthy relationship.

Rationale: Life events can affect people in different ways. Obstacles can challenge persons' choices of coping. How the persons perceive, cope, adjust and learn can affect their well-being, personal growth and life direction. Person-centered therapy presents the theory that reflects faith and positive view of humans' potentials to find their own productive solutions and pursue their self-actualization. Therapist is one professional helper who provides psychological supports to clients. Effective therapist communicates their positive human qualities and provides powerful therapeutic relationship, which enhances clients' deep self-exploration, self-acceptance, self-direction and self-responsibility to fulfill their full potentials. Person-centered therapy can be applied to deepening healthy relationships and can contribute to world peace.

Interest of this Article: This article introduces the concepts of person-centered therapy by presenting Carl Rogers's biography, Carl Rogers's faith in humans' qualities, therapeutic goals, qualities of therapist and therapeutic relationship and 3 crucial components for therapeutic condition: congruence, unconditional positive regard and empathic understanding. It presents how person-centered therapy can enhance humans' personal growth in the process to become self-actualized.

Purpose: This article aims to (1) explain the concepts of person-centered therapy and (2) link its contribution to humans' personal growth and positive relationship. 


\section{Person-Centered Therapy}

Carl Rogers's Biography: Carl Rogers (1902-1987) is a founder of person-centered therapy (Corey, 2005). His theory reflects his ways to overcome his own struggle to pursue healthy life and personal growth. In his biography, Carl Rogers (1961) viewed his family as loving, but religious. He also viewed his mother as 'judgmental' (Corey, 2005). His family life influenced him to be shy. In his childhood, he spent so much time reading, being with himself and reflecting his life. His interests in education had changed from agriculture to history, religion and clinical psychology respectively (Corey, 2005). Carl Rogers created person-centered therapy and emphasized the values of 'nonjudgmental listening and acceptance' (Heppner, Rogers, \& Lee, 1984 cited in Corey, 2005) to overcome his pain from judgmental mother. He had proved that he could maintain his faith in humans' values and positive view about life. Carl Rogers expanded his work contribution for world peace during his last 15 years of life. His work resulted in his nomination for 'the Nobel Peace Prize.' In 1987, Rogers passed away due to heart failure. He had proved to live according to concepts of his theory. He understood his true self. He felt confident in his beliefs. He was true to himself and other people (Corey, 2005). His own personal growth and work experiences have proved that his theory can enhance humans' life-long growth and healthy relationships, which can be applied to humans' life and world peace as he hopes.

Faith in Humans' Qualities: Rogers had faith in humans that all humans have their own potentials and ability to grow (Corey, 2005). Since person-centered therapy is based on humanistic psychology, which views humans positively, therapist's faith in humans' qualities can communicate to clients that they are valued for their goodness, potential and abilities. Faith opens opportunities for clients to grow while receiving therapist's appreciation for their personal growth. The basic assumption of person-centered therapy is that humans are 'trustworthy' and have their own capacity for self-understanding, 'selfdirecting,' pursuing personal growth and solving problem by themselves (Corey, 2005). Capuzzi \& Gross (1999) summarized 4 basic assumptions of Person-centered therapy as: (1.) humans are basically 'trustworthy,' (2.) humans have tendency to pursue 'self-actualization and health,' (3.) humans own 'inner resources' for 'positive directions' and (4.) humans "respond to their uniquely perceived world (phenomenological world)" (Capuzzi \& Gross, 1999). Carl Rogers believed in humans' 'trustworthiness and resourcefulness.' Humans have their own abilities for 'self-understanding,' 'self-directing,' creating changes and living healthy life (Cain, 1987 cited in Corey, 2005). Faith in humans' trustworthiness can communicate to others that they are trusted, valued, believed in, have adequate abilities and possess strength with inner power. Trust gives chances to others to handle life situation on their own. It can enhance confidence and courage. When the therapist trusts in clients' power to deal with their own issues effectively, therapist will be nondirective and allow clients to grow by him or herself. Clients will experience their own inner power and believe in their potential. Rogers (1980) explained, "Individuals have within themselves vast resources for self-understanding and for altering their self-concepts, basic attitudes, and self-directed behaviors" (Seligman, 2001). "His professional experience taught him that if one is able to get to the core of an individual, one finds a trustworthy, positive center" (Rogers, 1987 cited in Corey, 2005). Rogers had faith in humans that humans are 'good and trustworthy.' Humans are motivated to fulfill their 'goals' and be 'socially responsible' (Kottler \& Brown, 2000). Carl Rogers believes that humans possess their own inner resources to strive for good life direction. In order to grow, humans need to understand and use their resources. Overcoming pain and obstacles productively can strengthen and even expand humans' inner resources. When humans are aware and appreciate their inner power, they will be secure and become more confident. Person-centered therapy believes in human's 'dignity,' 'worth', 'right for their thoughts,' 'self-direction,' positive 'potential' for personal growth (Cain, 1987 in Seligman, 2001) and self-actualization tendency. The process toward self-actualization helps humans grow and improve their qualities. Self-actualization gives positive life direction and desirable qualities to fulfill one's potentials and live full life. Self-actualization can strengthen lifelong personal growth because it demands positive qualities and the perseverance of those positive qualities. It can be the goal that gives life direction. The Person-centered therapy values humans' sense of 'independence' and 'self-integration.' "Its focus is on the person, not on the person's presenting problem" (Corey, 2005).

Therapeutic Goals: Person-centered therapy aims to assist clients to be who they are and 'fulfill their unique potential' (Nelson-Jones, 2000). Combs (1989) explained that the goal of person-centered therapy is to make clients feel free for 'self-exploration' and 'self-direction' (Corey, 2005). Nelson-Jones (2000) 
proposed questions for self-reflection (1.) whether the persons can find their true self and be who they are, (2.) whether the persons can feel and act according to their true self or they still feel and act according to their parents' or other people's influences (Nelson-Jones, 2000). In addition, "PersonCentered Counseling views self-actualization (state of fully functioning person) as a practical and functional goal for treatment" (Bozarth \& Brodley, 1991 in Seligman, 2001). Therapist him/herself needs to be a 'fully functioning person' who lives healthy life and 'becomes a role model for clients' because the 'treatment goal' is to assist clients to become 'fully functioning persons' themselves (Seligman, 2001). The fully functioning persons need to possess mental health. They need to (1.) 'Open to experience,' (2.) 'Live with purpose' and (3.) 'Trust in oneself and other people' (Bozarth \& Brodley, 1991 in Seligman, 2001). Therapist helps clients understand their own qualities and 'values.' They will recognize their human qualities, which can lead to being kind to themselves and others (Kottler \& Brown, 2000). Therapist stimulates clients' personal growth and changes with self-responsibility (Corey, 2005). Since clients attend psychotherapy for specific time, clients need to learn to apply their skills and qualities to continue their life in healthy direction without therapist. The theory reflects an enhancement of humans' qualities as follows:

- Self-Exploration: Self-exploration can be done with self-awareness of one's own feelings, action, thoughts, qualities, potential and abilities. Life experiences can give information about oneself. The persons can observe themselves in various aspects in order to gain better self-exploration.

- Be Kind to Oneself and Others: Healthy self-love and an understanding of one's true self require kindness. The persons view themselves as humans who can make mistakes, have some fears and possess some weaknesses. Kindness can lead to letting go, forgiveness and flexibility. The persons who are kind to themselves can be kind to others because persons can give what they have. If they own kindness, they can express kindness to others. Kindness allows the persons to accept themselves and become brave to be who they are.

- Be Who They Are: What the persons think, act or say is the reflection of who they are. The self is a crucial psychological factor to live and to grow. Humans may not always live from their true self. Humans are social beings who can receive influences from other people, especially from parents and family. Humans need to search, recognize and understand their true self. It requires deep self-awareness, soul searching, self-acceptance, honesty, courage and healthy self-love. Humans who live honestly with their true self will feel free from other people's approvals, know what they stand for, can resist issues that are not true to their true self, feel secure and at peace from within. Knowing one's true self and connecting with others honestly are basic components for creating and maintaining healthy deep personal relationship.

- Fulfill One's Unique Potential: Humans have much potential, but may not use or live with their full potential. Humans need to explore themselves, take actions and give opportunities to experience many tasks. They will find themselves that they have abilities.

- Self-Direction: When humans know who they are and have their own life goals that reflect their true self, they create their self-direction to move toward their goals that can better fulfill their needs because their goals come from themselves, not from others.

- Self-Responsibility: Humans need to take responsibility for them. There can experience challenging or painful life events, but humans can take their own responsibility for their thoughts, actions and choices. Self-responsibility reflects that humans are taking control of their life without putting the blames to other people or external factors. They will feel the sense of inner power to choose how to handle their life condition. Self-responsibility is an active act, which the persons can take actions without waiting for anything.

\section{Qualities of the Therapists and Therapeutic Relationship}

Person-centered therapy believes that the qualities of the therapists and the therapeutic relationship are the most powerful tools to enhance clients' personal growth. Therapist him/herself is an important tool for therapy. Therapist can be a good role model for clients and provide healthy therapeutic relationship for clients to experience. Therapist him/she must possess 'self-awareness,' understands and has positive attitudes toward self, understands how other people view him/her, be one and be 'honest.' (Seligman, 2001). Bozarth et al. (2002) added, "It is a therapist's attitude and belief in the inner resources of the client that create the therapeutic climate for growth" (Corey, 2005). Humans naturally have needs for the 
sense of belonging and relationship in their life. Healthy relationship needs to be a mutual relationship, which demands 'acceptance of one's and others' uniqueness and needs' (Nelson-Jones, 2000). Carl Rogers confirmed his belief in the power of quality therapist and therapeutic relationship that according to his therapeutic experiences and teaching role that he gave his students a 'freedom to learn,' he noticed humans' potentials and motivation to become 'whole' and be 'actualized' (Nelson-Jones, 2000). Therapeutic relationship needs to provide 'trust, openness, acceptance, permissiveness, and warmth' to allow clients' changes and personal growth (Kottler \& Brown, 2000). Carl Rogers emphasizes human qualities of the therapist and the quality of therapeutic relationship that are powerful for clients' personal growth (Corey, 2005). It is very important that the therapist needs to acquire positive qualities and pursue his/her own personal growth, as Carl Rogers believed that qualities of the therapist could be communicated to clients. Examples of therapist's qualities are positive attitudes, trustworthy, openness, acceptance and warmth, believing in clients' potentials, acceptance of one's and others' uniqueness and needs and having faith in humans' potential and motivation to become actualized.

- Positive Attitudes: Therapist who maintains positive attitudes about oneself, humans, life and the world will be more open and acquires mental health. Positive attitudes toward others will be communicated to clients, which can create positive atmosphere for clients to reveal themselves.

- Trustworthy, Openness, Acceptance and Warmth: Therapist who is trustworthy, warm, open and accept clients will make clients become more open and be true to themselves which allows clients' self-understanding and self-directing to change and grow.

- Believing in Clients' Potential: Therapist who believes in clients' potential will influence clients to believe in themselves, gain positive view and value themselves more. Clients will be motivated to search for their potential and pursue their personal growth.

- Acceptance of One's and Others' Uniqueness and Needs: Each individual is unique. No one exactly feels, perceives, thinks, feels and needs in the same way. This fact helps the therapist becomes aware of his/her own and others' uniqueness and tries to understand clients' qualities and perspectives as who they are. The therapist tries to help clients understand their true self and accept themselves as unique and valuable persons.

- Having Faith in Humans' Potential and Motivation to Become Actualized: The therapist has and communicate faith in humans' potential to grow in order to live fuller life. This belief will allow the therapist to give opportunities for clients to grow.

Therapist will be the role model and can create therapeutic relationship that makes clients feel less defensive, feel warm, understanding and accepting. The experiences to interact with therapist and be in healthy therapeutic relationship can be powerful for clients to grow and change because clients may not usually experience this condition in their real life. Humans are social beings and need to grow in relationship with others. Clients need to learn to be their healthy self and be true to themselves while interacting or being in relationship with others without losing themselves. Clients can experience healthy therapeutic relationship and apply their skills to create and preserve healthy relationships in their life.

Congruence, Unconditional Positive Regard, Empathic Understanding: There are 3 core factors that therapists need to provide for their clients in order to enhance client's personal growth and healthy self. These 3 factors are "(1.) Congruence (genuineness, or realness), (2.) unconditional positive regard (acceptance and caring) and (3.) empathic understanding (an ability to deeply grasp the subjective world of another person)" (Corey, 2005). The therapist needs to provide positive condition with these 3 components. This condition is the necessity for 'therapeutic changes' (Rogers, 1957 in Nelson-Jones, 2000).

'Congruence': "Other words for congruence are genuineness, realness, openness, transparency and presence" (Nelson-Jones, 2000). According to Rogers, congruence is the most crucial factor for therapeutic relationship. The therapist needs to develop his/her own congruence in "what he/she is feeling on the inside and what he/she is communicating on the outside" (Kottler \& Brown, 2000). "People who are congruent" communicate, "their inner and outer selves are consistent and clear" (Seligman, 2001). It is crucial for the therapist to be 'real,' 'caring' and 'nonjudgmental' in order to create 'changes' in clients (Corey, 2005). When clients truly feel and sense the positive qualities of the therapist, clients 'will become less defensive and more open to themselves and their world' (Corey, 2005). Clients will reduce their defensiveness when the therapist is real to them (Nelson-Jones, 2000). Therapist needs to be 
competent, mature, and strong, maintain good mental health and be real to clients. Clients can sense the therapist's genuineness, which can create trust and sincerity. In order to create trust for clients, 2 ethical issues in psychology, which are confidentiality and informed consent, need to also be applied. "Confidentiality is both a legal and ethical issue" that is crucial for creating 'trust' in therapeutic relationship (Corey, 2005). There are exceptions to break confidentiality. These clients' 'circumstances' are (1.) "Harming to one or others, (2.) involving child abuse, elder abuse or abuse of dependent persons, (3.) being under 16 and being victim of incest, rape, child abuse or some other crime, (4.) Needing hospitalization, (5.) being court order, process or actions, (6.) releasing information to clients themselves or a third party" that clients require (Corey, 2005). Therapist does not disclose clients' issues to anyone except in the circumstances of the exception of confidentiality. Clients will feel safe to open and reveal their issues with therapist. Therapist also needs to show respect to clients' human dignity._In addition, "informed consent is an ethical and legal requirement" which can enhance trust in therapeutic relationship. The issues that need to be provided to clients are "general goals of therapy, the responsibilities of the therapist toward the client, the responsibilities of clients, limitations of and exceptions to confidentiality, legal and ethical issues, the qualifications and background of therapist, fee, services to be expected, length of therapy, benefits of therapy and risks involved and possibility to discuss client's case with colleagues or supervisors" (Corey, 2005). Informed consent creates sincerity, respect and honesty. Clients have their own rights to make decision to receive therapy. Both confidentiality and informed consent can make clients feel safe and trust their therapist along with therapist's congruence and sincerity to the clients.

'Unconditional Positive Regard': “Unconditional positive regard includes non-possessive warmth, caring, prizing, acceptance and respect" (Nelson-Jones, 2000). It reflects Carl Rogers's 'deep trust' in clients' own ability to grow and change when receiving 'nurturing condition.' The therapist needs to have faith in other humans' 'worth' (Nelson-Jones, 2000). Unconditional positive regard is communicated by therapist who is nonjudgmental. Clients will feel 'valued and cared for' which can promote clients' selfworth and 'self-acceptance' (Nelson-Jones, 2000). It implies that the therapist "views that clients try to do the best thing they can at the present time" (Seligman, 2001). "The therapist does not evaluate and judge clients' actions or statements; behavior is viewed neutrally, and all people are worthy of respect" (Kottler \& Brown, 2000). "Unconditional positive regard' shows 'respect and acceptance of clients for who they are' without pressuring them to 'please' the therapist. Warmth and positive regard help clients gain power to overcome problems pursue their own personal growth and 'become more fully functioning' (Seligman, 2001). When clients feel accepted and being cared as 'unconditional positive regard', clients will be more open to reveal and work on their issues (Capuzzi \& Gross, 1999) because unconditional positive regard conveys acceptance, caring, respect and no judgment. Clients will feel safe to explore and reveal their true self.

'Empathic Understanding': Words for meaning of Rogers' empathic understanding are "empathy, accurate empathy, empathic understanding, empathic responsiveness, an empathic way of being, an empathic stance, empathic attitude" (Nelson-Jones, 2000) and 'accurate empathic understanding' (Corey, 2005). "This denotes the process of attempting to understand, from the client's frame of reference, the thoughts and feelings underlying behavior - that is, the ability to walk around in the client's shoes and know how he or she feels" (Kottler \& Brown, 2000). "Empathic understanding implies that the therapist will sense clients' feelings as if they were his or her own without becoming lost in those feelings." It aims to stimulate clients to understand their true self deeply, to be aware and to cope with their own 'incongruity' (Corey, 2005). 'It refers to the understanding of the clients' world from the clients' point of view" (Capuzzi \& Gross, 1999). Therapist needs to communicate an understanding from 'clients' internal frame of reference' (Capuzzi \& Gross, 1999). Combs and Snugg (1959) described that other people explained one's behavior from their 'frame of reference' while the person oneself explained his/her own behavior from his/her 'internal frame of reference' (Nelson-Jones, 2000). Kottler and Brown (2000) added that one must "acknowledge the need to suspend one's own values and judgments as one encounter other persons so that one may experience their inner reality" (Kottler \& Brown, 2000). Therapist tries to understand clients as clients experience their world. Empathic understanding provides mental supports for clients that they are not alone. There is the therapist who listens and clients can share their life experiences with their therapist. Therapist needs to be aware that no one feels and perceives things exactly in the same way even though they experience the same event because each 
individual is unique with unique personality, perception and life experiences. The therapist employs sincere body language, probing, active listening, paraphrasing and reflection to help clients feel understood.

According to Watson (2002), 'empathic understanding' communicates an 'understanding of clients' feelings and experiences.' He believed that 'empathic understanding' is the most crucial aspect that affects 'clients' progress in therapy.' (Corey, 2005). However, 'no matter how empathic you try to be, you can still never really know the full experiences and perceptions of another person" (Kottler \& Brown, 2000). "No two people see the world exactly alike. No two people can be expected to see things as happening in exactly the same way" (Capuzzi \& Gross, 1999)._It is noted that it is hard to find the condition that provides genuineness, unconditional positive regard and empathic understanding in real life. Clients may never experience this condition in their real life. Therapeutic relationship can present the existence of this experience, which is very powerful for clients' changes and personal growth. It needs to also note that the therapist as a human being may not be able to provide genuineness, unconditional positive regard and empathic understanding at all time. As Sanford (1990) pointed out that "it is not realistic to expect that any therapist can be real, caring, understanding, and accepting all the time with all clients" (Corey, 2005). Rogers's research (1977) also accepted that even though 'caring, prizing, accepting and valuing clients in a non-possessive way' influenced 'successful therapy,' therapist may not 'genuinely feel acceptance and unconditional caring at all times' (Corey, 2005). However, therapist's self-awareness and commitment for personal growth can help therapist better provide desirable therapeutic relationship to clients.

\section{Person-Centered Therapy and Personal Growth}

Growing toward Self-Actualization: "Person-centered counseling views self-actualization (state of fully functioning person) as a practical and functional goal for treatment" (Bozarth \& Brodley, 1991 in Seligman, 2001). Bozarth \& Brodley (1991) stated, "Rogers's concept of the fully functioning person reflects his ideal of emotional health. Three personality dimensions are particularly characteristic: openness to experience, living with a sense of meaning and purpose, and trust in self and others" (Seligman, 2001). "It involves a tendency toward autonomy and self-regulation. Each person's path to it is unique" (Seligman, 2001). Humans with these qualities will have healthy autonomy, know who they are, feel the sense of belonging, have self-discipline, can create and maintain healthy relationship, can perform self-reflection, feel worthy, strive for self-actualization and pursue healthy life direction. They do not live for other people's approvals (Seligman, 2001). Person-centered therapy believes in humans' motivation to grow toward self-actualization. "The actualizing tendency is basically positive" (Nelson-Jones, 2000). Rogers trusted in humans' potential for self-control, self-discipline and self-direction. "All psychological difficulties are caused by blockages to this actualizing tendency." Thus, therapist's role is to help clients move these blockages (Nelson-Jones, 2000) by providing therapeutic condition that reduce clients' defensiveness and enhance deep self-exploration and self-understanding. Humans possess 'actualizing tendency', which make them become 'self-direct' and move 'away from external control' (Nelson-Jones, 2000). Broadley (1999) added that 'actualizing tendency' moves toward 'realization, fulfillment, autonomy, self-determination and perfection' while still maintaining 'relationships, interdependence, connection or socialization' (Corey, 2005). Rogers believed in humans' capacity and motivation to grow and pursue 'self-actualization' (Kottler \& Brown, 2000). Humans naturally pursue personal growth, good health and 'self-actualization' (Seligman, 2001). Self-actualization requires 'autonomy and self-regulation' (Seligman, 2001). Personal growth and self-actualization tendency can deepen personal relationship. Healthy true self enhances good personal relationship. Humans need quality relationship in their life to maintain mental health. "The capacity for good personal relationships incorporates Carl Rogers' notions of accepting others as unique individuals, prizing others, relating openly and freely to them on the basis of immediate experiencing, and having the capacity, when appropriate, to communicate a rich selfawareness. These relationships are characterized by mutual concern for both people's self-actualizing. Rogers considered congruence, genuineness or 'realness' to be probably the most important element in the ordinary interactions of life, while empathy has the highest priority where the other person's anxious and vulnerable" (Nelson-Jones, R., 2000). Person-centered therapy enhances humans' qualities: 
- Enhancing Self-Awareness: Person-centered therapy enhances 'self-awareness of 'feelings, personal growth and congruence.' It raises self-responsibility and 'active attitude toward life and personal growth' (Kottler \& Brown, 2000).

- Recognizing the Values of 'Congruence, Unconditional Positive Regard and Empathic Understanding': Person-centered therapy helps humans recognize and appreciate the values of 'congruence, unconditional positive regard and empathy' (Kottler \& Brown, 2000) in enhancing quality of relationship.

- Taking Self-Responsibility: Humans need to be responsible for self-learning and their own 'life experiences' (Kottler \& Brown, 2000). Self-responsibility implies the acceptance to be who they are and what they have done (Nelson-Jones, 2000). "Personal Responsibility implies selfcentered, self-help and personal power....within caring relationships. Acknowledgement of personal responsibility is a central part of the self-concepts of effective people" (Nelson-Jones, 2000)

- Understanding Feelings: Person-centered therapy helps humans understand their own feelings and 'sharing' feelings to others (Kottler \& Brown, 2000).

- Being Aware of One's Own Perspectives: It implies self-understanding and awareness of trying to understand oneself from one's own of reference and understand others from others' own of reference.

- Being 'Open to Experience': 'Openness to experience' implies that humans live from freedom of choice, 'be spontaneous,' 'be creative,' 'be alive,' can cope with 'changes' and be aware of 'choices' that affect 'their lives' (Nelson-Jones, 2000).

- Being 'Rational': 'Openness to experience' can release 'rationality' since Rogers believed that humans' defensiveness hinders 'rationality' (Nelson-Jones, 2000).

- Living Fuller Life: Self-actualized person can live fuller life (Nelson-Jones, 2000) and experience present moment fully. Humans cannot change the past. The future is not yet coming. The present time is the most powerful time for living.

- Choosing Positive Life-Direction: Self-actualized person can choose positive life direction (Nelson-Jones, 2000), choose positive coping and find better choice to deal with issues with selfresponsibility.

- Accepting One's and Others' Uniqueness (Nelson-Jones, 2000): Each human is unique. Selfactualized person accepts his/her own uniqueness and can accept others' uniqueness as well. "Self-acceptance means that people are less likely to be defensive and hence more likely to accept others" (Nelson-Jones, 2000).

- 'Prizing' One: The persons who 'possess unconditional self-regard and self-acceptance' can 'prize themselves' from their own inner 'values' (Nelson-Jones, 2000). They view themselves positively, can admire, appreciate, reward and value themselves from within. These qualities create the sense of security and freedom.

- 'Prizing Others' (Nelson-Jones, 2000): When humans feel secure and view them and others positively, they can appreciate and admire others without feeling threatened.

- Living Moral and Ethical Life: Self-actualized person take responsibility for themselves without hurting other people or invading others' rights. As Nelson-Jones (2000) explained that, the person realizes his/her own and other people's tendency toward 'self-actualization' and is careful not to invade other people's 'rights.' 'Ethical Living' requires 'spiritual values' and 'trust in internal rather than in external authority' (Nelson-Jones, 2000).

It is crucial to note that each person can have his/her own 'unique path' to reach self-actualization (Seligman, 2001). It reflects each individual's autonomy and uniqueness that need to be respected.

Discussion: Carl Rogers had applied his theory to his own personal growth and his life. He used himself along with his own observation and experimentation in applying his concepts to develop his own theory. As Corey (2005) pointed out that theories could express the theorists' real life, Carl Rogers' theory reflects his needs, pain and struggles. He created and received personal growth benefits from his own theory (Nelson-Jones, 2000) which can confirm and approve the effectiveness of his theory to enhance personal growth. It implies that pain and negative life experiences can be the necessary ingredients to motivate humans to strive towards personal growth by turning negative issues to positive life learning which can deepen meaning, values and happiness. Pain and obstacles can test humans and allows humans 
to understand their true self, potentials and inner strengths. Carl Rogers's theory not only emerges from his intellectual and cognitive ability, but also from his heart, faith, humans' qualities and his work passion to help other humans grow.

\section{Conclusion}

Person-centered therapy was introduced by Carl Rogers who fulfilled his own personal growth from conducting this theory that tried to overcome his own struggles, personal issues and needs. Pains and obstacles can be the important ingredients to stimulate humans' personal growth. Carl Rogers has faith in humans' qualities that humans are basically trustworthy, have tendency to pursue self-actualization and possess inner resource to grow. The therapeutic goals are assisting clients to be who they are, fulfill their potential and grow toward self-actualization. Person-centered therapy emphasizes that the qualities of therapists and the therapeutic relationship are more powerful and important than therapeutic techniques. Carl Rogers presented 3 core conditions to help clients grow. These 3 core conditions are congruence, unconditional positive regard and empathic understanding. Therapeutic condition and relationship will enhance clients' self-direction, self-responsibility, self-awareness to be true self and live toward their full life. Person-centered concepts can be applied to deepen relationship and enhance humans' qualities toward self-actualization as having self-awareness, recognizing the values of congruence, unconditional positive regard and empathic understanding, taking self-responsibility, understanding feeling, being aware of one's own perspectives, being open, being rational, living fuller life, choosing positive life-direction, accepting one's and others' uniqueness, rewarding oneself, rewarding others and living moral and ethical life. It is noted that since each individual is unique, each person's pathway to become self-actualized person is unique.

\section{References}

Bozarth, J. D. \& Brodley, B. T. (1991). Actualization: A Functional Concept in Client- Centered Therapy, in Seligman, L. (2001). Systems, Strategies and Skills of Counseling and Psychotherapy, New Jersey: Merrill - Prentice Hall, Inc.

Bozarth, J. D., Zimring, F. M. \& Tausch, R. (2002). Client-Centered Therapy: The Evolution of a Revolution, in Corey, G. (2005). Theory and Practice of Counseling \& Psychotherapy ( $7^{\text {th }}$ Ed) (International Student Edition), Belmont, California: Brooks/Cole -Thomson Learning.

Broadley, B. T. (1999). The Actualizing Tendency Concept in Client-Centered Theory, in Corey, G. (2005). Theory and Practice of Counseling \& Psychotherapy ( $7^{\text {th }}$ Ed) (International Student Edition), Belmont, California: Brooks/Cole -Thomson Learning.

Cain, D. J. (1987). Carl R. Rogers: The Man, His Vision, His Impact, in Corey, G. (2005). Theory and Practice of Counseling \& Psychotherapy $\left(7^{\text {th }}\right.$ Ed) (International Student Edition), Belmont, California: Brooks/Cole - Thomson Learning.

Cain, D. J. (1987). Carl R. Rogers: The Man, His Vision, His Impact, in Seligman, L. (2001). Systems, Strategies, and Skills of Counseling and Psychotherapy, New Jersey: Merrill - Prentice Hall, Inc.

Capuzzi, D. \& Gross, D. R. (1999). Counseling \& Psychotherapy: Theories and Interventions (2nd Ed), New Jersey: Merrill - Prentice Hall, Inc.

Combs, A. W. (1989). A Theory of Therapy: Guidelines for Counseling Practice, in Corey, G. (2005). Theory and Practice of Counseling \& Psychotherapy ( $7^{\text {th }}$ Ed) (International Student Edition), Belmont, California: Brooks/Cole -Thomson Learning.

Combs, A. W. \& Snugg, D. (1959). Individual Behavior. (Rev. Edu.), in Nelson-Jones, R. (2000). Six Key Approaches to Counseling \& Therapy, London: Continuum.

Corey, G. (2005). Theory and Practice of Counseling \& Psychotherapy ( $7^{\text {th }}$ Ed) (International Student Edition), Belmont, California: Brooks/Cole-Thomson Learning.

Heppner, R. R., Rogers, M. E. \& Lee, L. A. (1984). Carl Rogers: Reflections on His Life, in Corey, G. (2005). Theory and Practice of Counseling \& Psychotherapy ( $7^{\text {th }}$ Ed) (International Student Edition), Belmont, California: Brooks/Cole-Thomson Learning.

Kottler, J. A. \& Brown, R. W. (2000). Introduction to Therapeutic Counseling: Voices from the field (4th Ed), Belmont, California: Wad worth/Thomson Learning.

Nelson-Jones, R. (2000). Six Key Approaches to Counseling \& Therapy, London: Continuum. 
Rogers, C. R. (1957). The Necessary and Sufficient Conditions of Therapeutic Personality Change, in Nelson-Jones, R. (2000). Six Key Approaches to Counseling \& Therapy, London: Continuum.

Rogers, C. (1961). On Becoming a Person, in Corey, G. (2005). Theory and Practice of Counseling \& Psychotherapy ( $7^{\text {th }}$ Ed) (International Student Edition), Belmont, California: Brooks/ColeThomson Learning.

Rogers, C. (1977). Carl Rogers on Personal Power: Inner Strength and Its Revolutionary Impact, in Corey, G. (2005). Theory and Practice of Counseling \& Psychotherapy (7th Ed) (International Student Edition), Belmont, California: Brooks/Cole-Thomson Learning.

Rogers, C. R. (1980). A Way of Being, in Seligman, L. (2001). Systems, Strategies and Skills of Counseling and Psychotherapy, New Jersey: Merrill - Prentice Hall, Inc.

Rogers, C. R. (1987). Rogers, Kohut, and Erickson: A Personal Perspective on Some Similarities and Differences, in Corey, G. (2005). Theory and Practice of Counseling \& Psychotherapy ( $7^{\text {th }}$ Ed) (International Student Edition), Belmont, California: Brooks/Cole-Thomson Learning.

Sanford, R. (1990). Client-Centered Psychotherapy, in Corey, G. (2005). Theory and Practice of Counseling \& Psychotherapy (7th Ed) (International Student Edition), Belmont, California: Brooks/ColeThomson Learning.

Seligman, L. (2001). Systems, Strategies and Skills of Counseling and Psychotherapy, New Jersey: Merrill Prentice Hall, Inc.

Watson, J. C. (2002), Re-visioning Empathy, in Corey, G. (2005). Theory and Practice of Counseling \& Psychotherapy $\left(7^{\text {th }}\right.$ Ed) (International Student Edition), Belmont, California: Brooks/ColeThomson Learning. 